\title{
Solar thermoelectric cooling technology applied to transport of vaccines in isolated communities
}

\author{
Juan José Milón Guzmán ${ }^{1, *}$, Sergio Leal Braga ${ }^{2}$, Juan Carlos Zúniga Torres ${ }^{1}$, and Herbert Jesús Del Carpio Beltrán ${ }^{1}$ \\ ${ }^{1}$ Universidad Tecnológica del Perú, Peru \\ ${ }^{2}$ Pontifícia Universidade Católica do Rio de Janeiro, Brasil
}

\begin{abstract}
A thermoelectric cooling system supplied by photovoltaic solar energy was built and evaluated with different thermal loads. The thermoelectric cooling module consumes $70 \mathrm{~W}$, it is supplied by a photovoltaic system of $90 \mathrm{~W}$ and 40 Ah battery. The voltage and electrical current in each component (panels, battery, and electric charge) has been measured. The tests were performed with different thermal loads placed in glass containers used for vaccines. To analyze the cooling and preservation process, the experiments were started at room temperature. The results show that the thermoelectric cooling system works for small thermal loads, and it could be applied to transport vaccines in isolated areas where people carry medicines in small containers that do not maintain the temperature necessary for the conservation of vaccines.
\end{abstract}

\section{Introduction}

The cold chain is a fundamental part of the conservation of medicines. In 2016, in the north of Peru 88,500 vaccines were lost due to the cold chain rupture. Around 1.5 million children die every year from diseases that could be prevented by a good distribution of vaccines. The main problem is the shipping logistics: the costs are not negligible and there is lack of human resources to ensure the distribution. The World Health Organization Health estimates that approximately $50 \%$ of vaccines are lost worldwide due to problems with temperature control, logistics and shipments. Conventional cooling systems require electrical power to operate and are not mobile.

\subsection{Thermoelectric solar photovoltaic cooling}

This process consists on cooling by allowing an electric current between two different conductors and depends solely on the type of material of the joint. It has a series of effects such as Joule effect, the Seebeck effect, the Peltier effect and thermal conduction. This makes it possible for two plates to be at different temperatures [1] [2]. The lower temperature sink removes heat from the higher temperature sink [3]. The power supply for these devices is in direct current, usually at $12 \mathrm{~V}$, which is also characteristic of photovoltaic systems. Nowadays, thermoelectric systems can be supplied with photovoltaic solar energy to cool photovoltaic panels [4] [5] [6] [7] [8], improve efficiency and lengthen the useful life that can be diminished due to the high working temperatures [9] [10] [11]. The application of thermoelectric cooling in buildings is under investigation [12] [13] [14], mainly due to the low cooling capacity of these systems (from
$3{ }^{\circ} \mathrm{C}$ to $4{ }^{\circ} \mathrm{C}$ ) with respect to the ambient temperature and energy availability in the area [15].

A trend to integrate these cooling systems to other technologies (as complementary systems) to improve thermal comfort has been observed [1] [16]. It is feasible to use a thermoelectric cooling system that uses photovoltaic energy because it is compact, light, and silent [13] [16] [17] and does not require conventional energy for its operation in isolated areas, for example [18] [19].

Keeping the cold chain of medicines uninterrupted is the most important factor to continue the immunization of patients. It prevents the drugs from losing their properties, since, without proper transportation and handling, medications can lose effectiveness and cause diseases and skepticism in the population [20].

Thus, coupling between the photovoltaic solar energy source and the thermal load for thermoelectric cooling can be implemented in isolated areas where energy resources are limited and the transportation of medicines requires cooling during long periods, this is, maintaining the cold chain uninterrupted to ensure the effectiveness of medications.

\section{Experimental model}

The experimental model is described in Figure 1. It is composed by the photovoltaic panel, the charge controller, the battery and the Peltier module in the insulated container (Figure 2).

*Corresponding author: jmilon@utp.edu.pe 
Photovoltaic panel

(60 W, Monocrystalline Silicon)

Charge Controller

$(12 \mathrm{~V})$

Battery

$(12 \mathrm{~V}, 40 \mathrm{ah})$

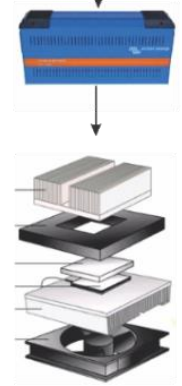

Fig. 1. Experimental Model.

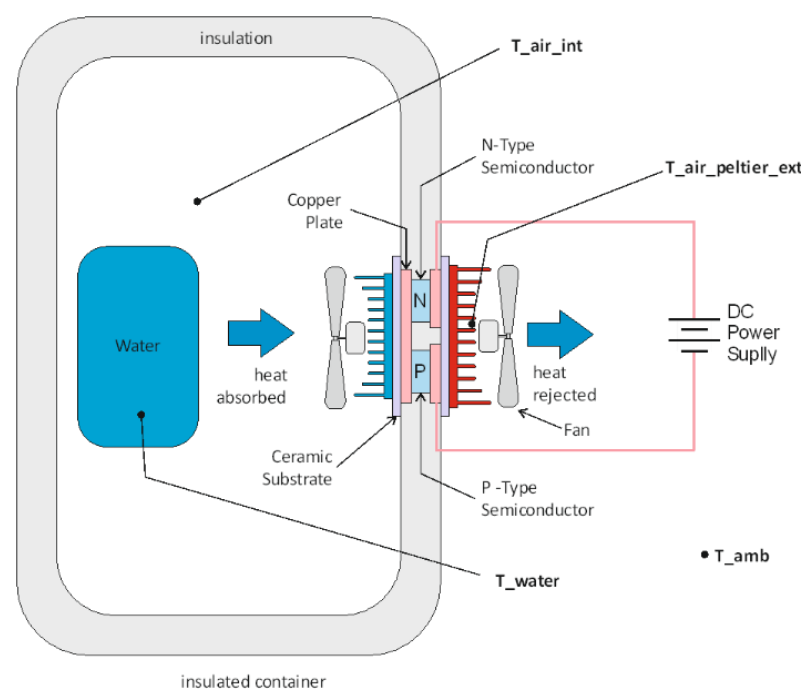

Fig. 2. Vaccine container.

The characteristics of the photovoltaic panel are detailed in Table 1.

Table 1. Photovoltaic panel characteristics.

\begin{tabular}{ll}
\hline \multicolumn{1}{c}{ Parameter } & \multicolumn{1}{c}{ Value } \\
\hline Model & CYC-90-12 \\
Output power & $90 \mathrm{~W} \pm 5 \mathrm{~W}$ \\
Unit efficiency & $15 \%$ \\
Nominal voltage & $17.2 \mathrm{~V}$ \\
Nominal current & $5.23 \mathrm{~A}$ \\
Open circuit voltage & $21.2 \mathrm{~V}$ \\
Short circuit current & $5.86 \mathrm{~A}$ \\
\hline
\end{tabular}

The electric load controller brand is PROSTAR; it works in the interval from $12 \mathrm{~V}$ to $24 \mathrm{~V}(0.1 \%)$ for a maximum load of $200 \mathrm{~W}$. The battery brand is RITAR and has the following characteristics.
Table 2. Characteristics of the battery.

\begin{tabular}{ll}
\hline Parameter & Value \\
\hline Model & R12-40 \\
Number of cells & 6 \\
Voltage & $12 \mathrm{~V}$ \\
Capacity & $40 \mathrm{~A} \cdot \mathrm{h}$ \\
Weight & Approx. $13 \mathrm{~kg}$ \\
Maximum discharging current & $400 \mathrm{~A}$ \\
& $13.6 \mathrm{~A}$ and 13.8 \\
Charging current and voltage & $\mathrm{V}$ \\
\hline The Peltier module is described in Table 3.
\end{tabular}

Table 3. Peltier module.

\begin{tabular}{ll}
\hline Parameter & Value \\
\hline Model & TEC1-12706 \\
Material & Ceramic \\
Hot plate temperature & $50{ }^{\circ} \mathrm{C}$ to $57^{\circ} \mathrm{C}$ \\
Temperature difference & $66-75^{\circ} \mathrm{C}$ \\
Maximum current & $6.4 \mathrm{~A}$ \\
Nominal voltage & $12 \mathrm{~V}$ \\
Maximum voltage & $16.4 \mathrm{~V}$ \\
Nominal power & $72 \mathrm{~W}$ \\
Resistance & 1.98 to $2.30 \mathrm{Ohm}$ \\
\hline
\end{tabular}

A transducer was used to measure the electric current. It is described in Table 4.

Table 4. Characteristics of the transducer.

\begin{tabular}{ll}
\hline Parameter & Value \\
\hline Model & ACS712 \\
Output voltage & $66 \mathrm{mV} / \mathrm{A}$ \\
Input voltage & $4.5 \mathrm{~V}$ to $5.5 \mathrm{~V}$ \\
Bandwidth & $80 \mathrm{kHz}$ \\
Uncertainty & $1.5 \%$ at $25^{\circ} \mathrm{C}$ \\
Internal resistance & $1.2 \mathrm{~m} \Omega$ \\
Output sensitivity & $66 \mathrm{mV} / \mathrm{A}$ to $185 \mathrm{mV} / \mathrm{A}$ \\
\hline
\end{tabular}

A $0.1 \mathrm{~mm}$ diameter Teflon-coated $\mathrm{K}$ type thermocouple was used to measure the temperature. For the measurement of solar irradiation, a pyranometer was used. It is described in Table 5.

Table 5. Characteristics of the pyranometer.

\begin{tabular}{ll}
\hline Parameter & Value \\
\hline Model & SP-110 \\
Sensitivity & $0.2 \mathrm{mV}$ per W \\
Precision & $\pm 5 \%$ \\
Measurement interval & $0 \mathrm{a} 400 \mathrm{mV}$ \\
Response time & $1 \mathrm{~ms}$ \\
Vision angle & $180^{\circ}$ \\
Spectral interval & $360 \mathrm{~nm}$ to $1120 \mathrm{~nm}$ \\
\hline
\end{tabular}


The Data Acquisition System (DAS) was an HP Agilent model 34970A. It contained three slots, a digital 6-digits multimeter and 8 plug-in switch and control modules. The DAS acquires the signals from thermocouples, RTD and thermistors, as well as DC/AC tensions, resistance of 2 and 4 threads, frequency and periods.

The parameters under study are:

$$
\text { Solar Power }
$$$$
\mathrm{P} \_\mathrm{S}_{\mathrm{S}}=\mathrm{I} \times \mathrm{A}
$$

Where:

$\mathrm{I}=$ Solar irradiation $\left[\mathrm{W} / \mathrm{m}^{2}\right]$

$\mathrm{A}=\mathrm{PV}$ module area $\left[\mathrm{m}^{2}\right]$

Electric power of the PV panel

$\mathrm{P}_{\mathrm{PV}}=\mathrm{I}_{\mathrm{PV}} \times \mathrm{V}_{\mathrm{PV}}$

Where:

I_pv $=$ PV panel current $[\mathrm{A}]$

$\mathrm{V} \_\mathrm{pv}=\mathrm{PV}$ panel voltage $[\mathrm{V}]$

Battery power

P_bat $=$ I_bat $\times$ V_bat

Where:

I_bat = Battery current $[\mathrm{A}]$

$\mathrm{V} \_$bat $=$Battery voltage $[\mathrm{V}]$

Peltier power

$\mathrm{P} \_$peltier $=\mathrm{I} \_$peltier $\times \mathrm{V} \_$peltier

Where:

I_peltier $=$ Peltier current $[\mathrm{A}]$

$\mathrm{V} \_$peltier $=$Peltier voltage $[\mathrm{V}]$

Fan power

$P \_f=I \_f \times V \_f$

Where:

I_f $=$ Fan current $[\mathrm{A}]$

$\mathrm{V}_{-} \mathrm{f}=$ Fan voltage $[\mathrm{V}]$

Thermal power

P_therm $=\left(\frac{m}{t}\right) \times C p \times \Delta T$

Where:

$\mathrm{m}=$ Mass $[\mathrm{kg}]$

$\mathrm{t} \quad=$ Time $[\mathrm{s}]$

$\mathrm{Cp}=$ Specific heat $\left[\frac{\mathrm{J}}{\mathrm{kg}^{\circ} \mathrm{C}}\right]$

$\Delta T=$ Temperature variation $\left[{ }^{\circ} \mathrm{C}\right]$

PV panel efficiency

$\eta_{\mathrm{pv}}=\frac{\mathrm{P} \_\mathrm{pv}}{P S}$

Where:

P_pv= PV panel power [W]
$\mathrm{P}_{\mathrm{S}}=$ Solar power $[\mathrm{W}]$

Controller efficiency

$\eta \_$cont $=\frac{\text { P_peltier }}{P_{-} p v}$

Where:

$\mathrm{P}$ _peltier $=$ Peltier power $[\mathrm{W}]$

$\mathrm{P}_{\mathrm{p} p \mathrm{p}}=\mathrm{PV}$ power $[\mathrm{W}]$

Thermal efficiency

$\eta_{-}$therm $=\frac{P_{-} \text {therm }}{\left(P_{-} p v+P_{-} b a t+P_{-} f\right)}$

Where:

P_therm $=$ Thermal power $[\mathrm{W}]$

$P_{-p v}=$ PV power $[\mathrm{W}]$

P_bat $=$ Battery power $[\mathrm{W}]$

$\mathrm{P}_{-} \mathrm{f}=$ Fan power $[\mathrm{W}]$

Global Efficiency

$\eta \_$global $=\frac{\text { P_therm }}{P_{-} s}$

Where:

P_therm $=$ Thermal power $[\mathrm{W}]$

$\mathrm{P}_{-}=$Solar power $[\mathrm{W}]$

\section{Results and analysis}

Different thermal loads (medicines) were simulated using deposits containing water. Different scenarios for transport were analyzed.

Different situations were analyzed for isolated areas: The first one is considering transport without electricity supply, that is, considering only solar energy as an energy source. As the second alternative is considering the transport in a vehicle that may have a source of $12 \mathrm{~V}$. As the third option is considering a source of power in residential AC $(220 \mathrm{~V})$. The last option is considering only the battery as an energy source as this value will determine the autonomy for transports where there is no energy source.

In cases where the energy supply is performed through a conventional energy source, such as, electricity coming from a carrier vehicle or from the public electric grid, the thermoelectric cooling system works as well. In this situation, usual in medical centers, hospitals and shelters, energy is not scarce and a battery is not necessary. Nevertheless, when the medicine load has to be transported and conventional electricity or solar energy are not available, a battery would be necessary.

The results shown below consider the use of solar energy and the assistance of a battery. In the different experiences performed, two typical cases are studied: (i) the supply of energy by the photovoltaic system and (ii) the supply by the photovoltaic system and the battery. Finally, an analysis of autonomy for medicine conservation is performed.

Figure 3 shows the variation of temperature for a thermal load of $216 \mathrm{~g}$ that has to attain a temperature of $5{ }^{\circ} \mathrm{C}$. In $1 \mathrm{~h} 10$, the conservation temperature was attained. 
The ambient temperature reached $22{ }^{\circ} \mathrm{C}$ and the one of the external air (Peltier), $25^{\circ} \mathrm{C}$. It can be observed that the internal temperature of the chamber is always below the thermal load temperature. For all the experiences performed, the cooling time was reasonable.

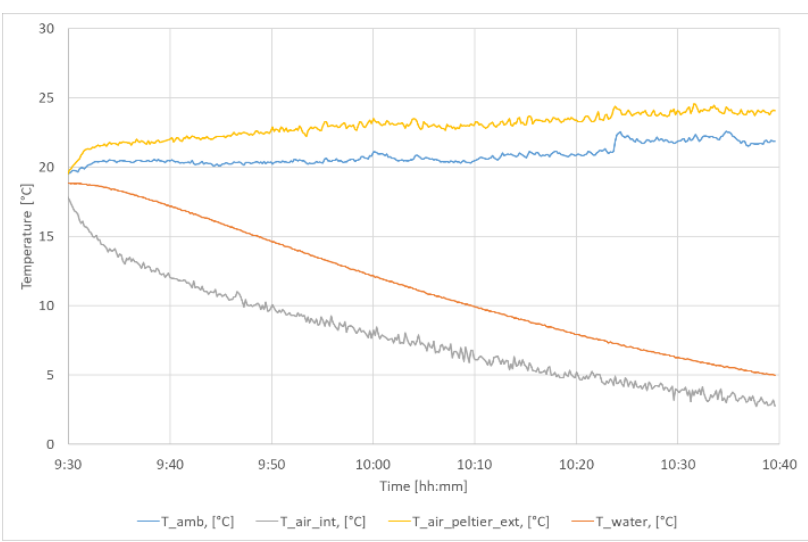

Fig. 3. Temperature variation during the cooling process. Thermal load: $216 \mathrm{~g}$.

Figure 4 shows the variation of voltage during cooling. Three values are presented: the PV panel voltage, the battery voltage and the Peltier voltage. All the values shown for the experience correspond to a thermal load of $216 \mathrm{~g}$. It can be seen that the PV panel voltage is higher than the battery's, which is, in turn, higher than the Peltier's. The values of the thermal load are in the admissible interval for a correct functioning (between 8 and $15 \mathrm{~V})$.

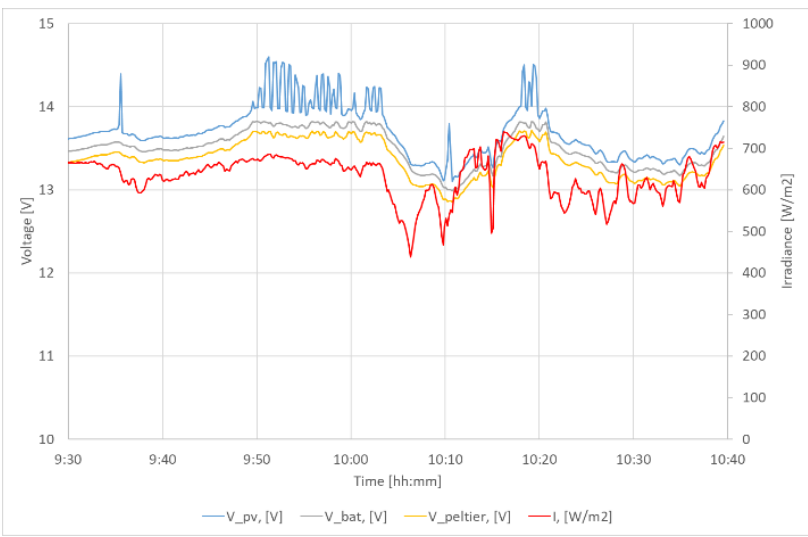

Fig. 4. Voltage variation. Thermal load: $216 \mathrm{~g}$.

Figure 5 shows the variation of current in the different components. Even though the output of electric current of the photovoltaic panel is variable (depending on the available solar power), the battery compensates the load and supplies the Peltier with a mostly stable current, avoiding variations that may affect the cooling process.

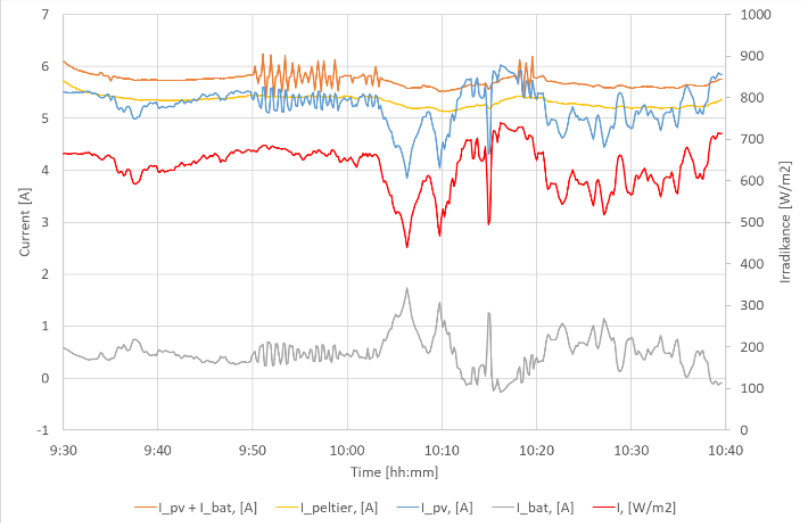

Fig. 5. Electric current variation. Thermal load: $216 \mathrm{~g}$.

Figure 6 shows the variation of the power of the different components of the system. It can be seen that the battery and the photovoltaic generator supply the energy to the Peltier cooling system. This electrical power is transformed into thermal power for the thermoelectric cooling process. It is also observed that the electrical power in the Peltier is approximately $70 \mathrm{~W}$ from which only a fraction $(5 \mathrm{~W})$ is transformed into thermal power. This would indicate a low efficiency in the process of heat transmission from the cold air to the thermal load (water). The thermal power depends on the efficiency of the heat transfer process and on the amount of medicine packaging, material and thickness, among others.

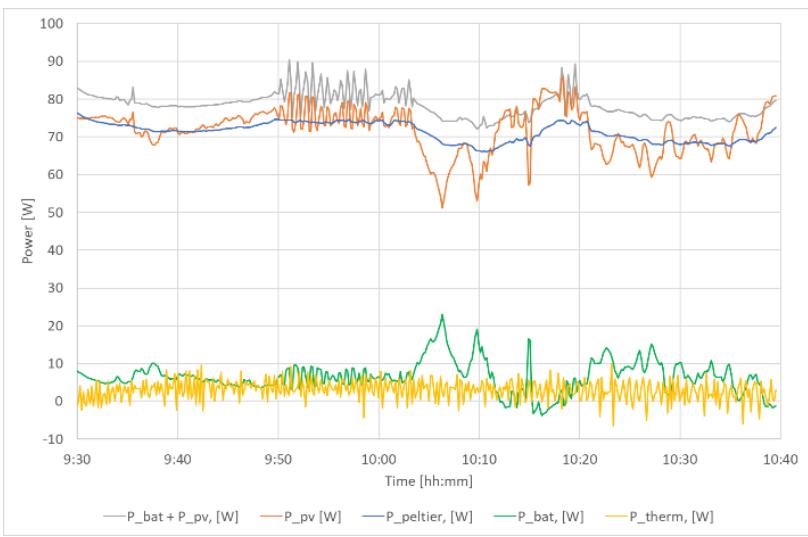

Fig. 6. Power variation. Thermal load: 216 g.

Figure 7 shows the variation of efficiency for the different components. Due to the technology used in the photovoltaic panel (mono-crystalline), the efficiency does not exceed $18 \%$. The efficiency of the charge controller is high $(90 \%)$, however, the thermal power does not exceed $4 \%$. It is noted that thermal efficiency depends on the global coefficient of heat exchange, which is part of the cooling phenomenon and is not related to Peltier technology.

The design of medicine packaging could improve the transmission of heat and therefore enhance the conservation of medicines, however, since sanitary properties of packaging are a more important issue than heat transfer properties, glass containers are the ones that 
are generally used for this, even if it is not the best material for heat conduction.

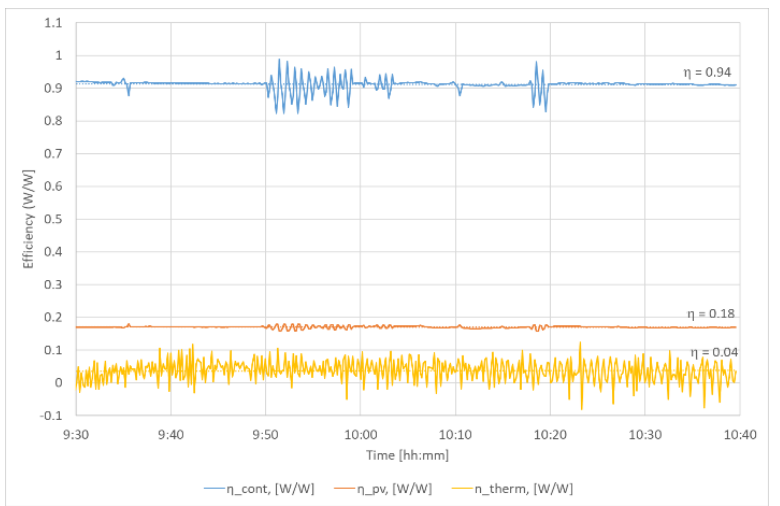

Fig. 7. Efficiency variation. Thermal load: 216 g.

Figure 8 shows the thermal efficiency compared to the overall efficiency. It can be seen that the overall efficiency does not exceed $1 \%$. This apparently low value is due to all the efficiencies in the different components, mainly the one of the photovoltaic panel. It is noted that solar energy allows for better efficiencies in systems that use electrical energy. This is to say, in this case, the quality of the energy and the heat transmission process considerably affect the efficiencies, but are not taken into account for the calculation.

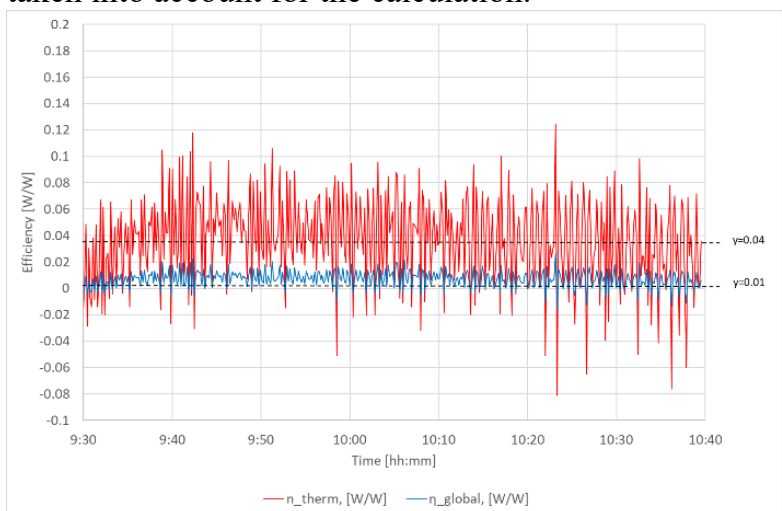

Fig. 8. Global efficiency variation. Thermal load: 216 g.

Figure 9 shows the cooling results for different thermal loads. The tests were performed in the same operating conditions (solar radiation and ambient temperature) to guarantee the reliability of the results. It can be seen that the cooling time for conservation varies according to the thermal load.

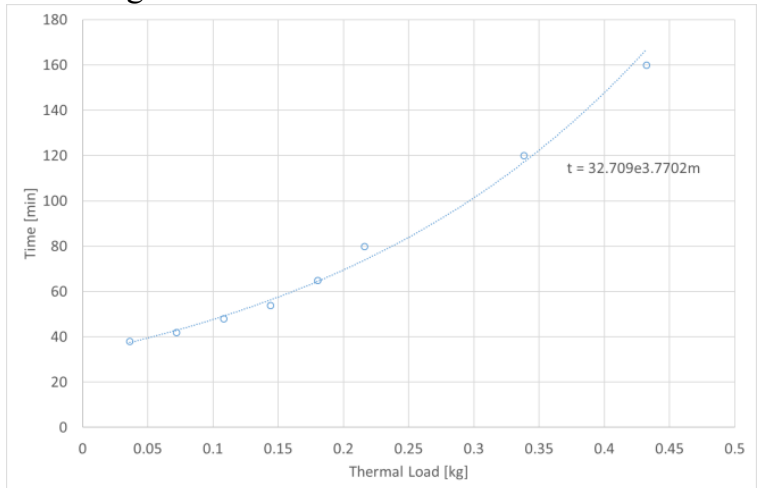

Fig. 9. Cooling time for different water thermal loads.
Figure 10 shows the variation of the electric current and the electrical power of the Peltier for different thermal loads. The current generated by the photovoltaic panel remains almost constant for all cases and the current that the battery supplies increases as the energy demand of the thermal load increases. The power consumed by the Peltier system increases with the thermal load between $60 \mathrm{~W}$ and $80 \mathrm{~W}$. It is shown that the power generated by the photovoltaic panels is sufficient to supply a thermal load starting at $36 \mathrm{~g}$.

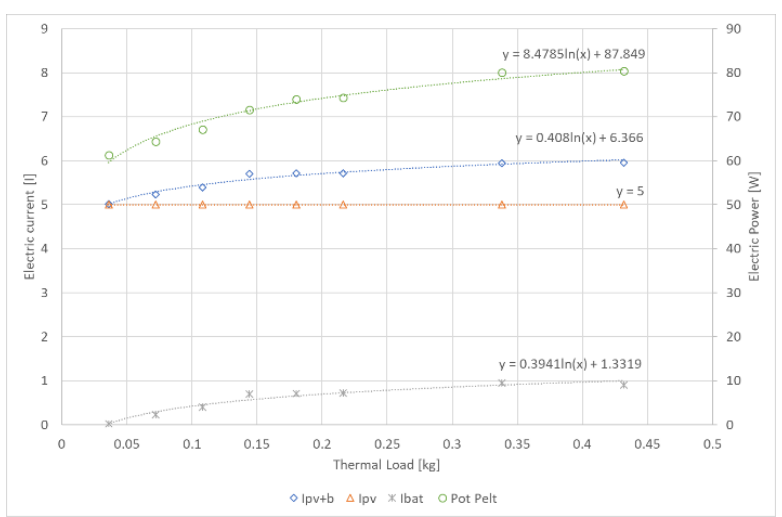

Fig. 10. Electric current and power for different water thermal loads.

Figure 11 shows the variation of the efficiency (thermal and global) for different thermal loads: The maximum thermal efficiency $(5.2 \%)$ corresponds to the maximum load and to a maximum overall efficiency of $1.5 \%$.

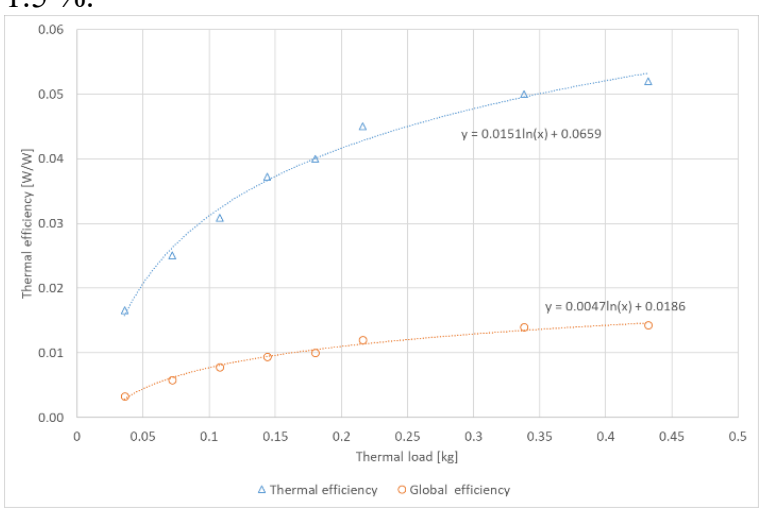

Fig. 11. Efficiency variation for different thermal loads.

\subsection{Autonomy assessment}

The autonomy of the system was evaluated with a battery of $12 \mathrm{~V}$ and $40 \mathrm{~A} \cdot \mathrm{h}$. The results indicate that in the conservation process at $5{ }^{\circ} \mathrm{C}$, the cooling autonomy with the exclusive use of the battery varies between $5 \mathrm{~h}$ and 6 $\mathrm{h}$, depending on the thermal load. It should be noted that, in the process of medicine conservation, the battery only supplies energy to replace losses due to thermal insulation: no openings in the conservation cavity have been considered. A battery of greater capacity implies greater autonomy, but it represents more weight. All 
these considerations must be taken according to the application available.

\subsection{Considerations for Transportation}

In the present study, the weight of the components necessary to conserve the medicines has been reduced. The medicine container weighs $1 \mathrm{~kg}$ including the medicines, the battery weighs approximately $13 \mathrm{~kg}$ and the photovoltaic panel weighs approximately $8 \mathrm{~kg}$, thus, all the cooling module weighs around $22 \mathrm{~kg}$. This weight could be assumed by a person, however, the long journey made by people in charge of the distribution of medicine has not been considered. Some other important points are the geography which lengthens the access to these areas, and the temperature and the humidity that affect considerably the load capacity. It is possible to reduce the weight of the photovoltaic panel by replacing it with a flexible system and, depending on the application reduce the battery size. The initial estimations conclude that the weight of a mobile prototype could reach up to $7 \mathrm{~kg}$ approximately; this is a more reasonable weight for someone to carry. In stationary applications, there are thermoelectric cooling systems of up to $500 \mathrm{~W}$. From this value, Peltier cooling systems are inefficient and a system that uses a steam compression cycle supplied with photovoltaic solar energy could be considered instead.

\section{Conclusions}

The Peltier system maintains the cold chain for medicine cooling and preservation. It is necessary to emphasize that Peltier systems can work with photovoltaic energy for transportation when there is no other available energy sources. The experiences carried out during the present study are oriented to situations where medicine or vaccines have to be supplied in distant locations that lacking energy resources that could allow the maintenance of conservation conditions.

The results also indicate a possible application to light-weight transportation systems, that is, situations in which someone has to transport a container and the photovoltaic energy supply system could be carried in a backpack, for example.

In the present study, a cooling technique has been developed for liquids. The efficiency is low due to the global coefficient of heat exchange determined by the thermal conductivity of the medicine container (glass), the air-glass convection coefficient and the thermal conductivity of the liquid. An important conclusion is that the most efficient application of this technology is for gas cooling, that is, in a next stage of this study, the application for air conditioning and thermal comfort will be studied.

\section{Acknowledgement}

This project was sponsored by the RED CYTED 717RTO535 - STORAGE OF SOLAR ENERGY FOR ISOLATED COMMUNITIES - AESCA.

\section{References}

1. A. Zuazua-Ros, C. Martín-Gómez, E. Ibañez-Puy, M. Vidaurre-Arbizu, and Y. Gelbstein, "Investigation of the thermoelectric potential for heating, cooling and ventilation in buildings: Characterization options and applications," Renew. Energy, vol. 131, pp. 229-239, 2019.

2. A. Benyoussef et al., "Thermoelectric cooling micro-inverter for PV application," Sol. Energy Mater. Sol. Cells, vol. 180, no. January, pp. 311321, 2017.

3. I. Sarbu and C. Sebarchievici, "Chapter 8 - Solar Electric Cooling Systems,” I. Sarbu and C. B. T.-S. H. and C. S. Sebarchievici, Eds. Academic Press, 2017, pp. 315-346.

4. K. Teffah and Y. Zhang, "Modeling and experimental research of hybrid PV-thermoelectric system for high concentrated solar energy conversion," Sol. Energy, vol. 157, pp. 10-19, 2017.

5. H. Najafi and K. A. Woodbury, "Optimization of a cooling system based on Peltier effect for photovoltaic cells," Sol. Energy, vol. 91, pp. 152 $160,2013$.

6. M. Hasanuzzaman, A. B. M. A. Malek, M. M. Islam, A. K. Pandey, and N. A. Rahim, "Global advancement of cooling technologies for PV systems: A review," Sol. Energy, vol. 137, pp. 25 45, 2016.

7. N. Dimri, A. Tiwari, and G. N. Tiwari, "Effect of thermoelectric cooler (TEC) integrated at the base of opaque photovoltaic (PV) module to enhance an overall electrical efficiency," Sol. Energy, vol. 166, no. November 2017, pp. 159-170, 2018.

8. P. Huen and W. A. Daoud, "Advances in hybrid solar photovoltaic and thermoelectric generators," Renew. Sustain. Energy Rev., vol. 72, no. September, pp. 1295-1302, 2017.

9. M. Benghanem, A. A. Al-Mashraqi, and K. O. Daffallah, "Performance of solar cells using thermoelectric module in hot sites," Renew. Energy, vol. 89, pp. 51-59, 2016.

10. L. Idoko, O. Anaya-Lara, and A. McDonald, "Enhancing PV modules efficiency and power output using multi-concept cooling technique," Energy Reports, vol. 4, pp. 357-369, 2018.

11. P. Pounraj et al., "Experimental investigation on Peltier based hybrid PV/T active solar still for enhancing the overall performance," Energy Convers. Manag., vol. 168, no. April, pp. 371-381, 2018.

12. P. Piantanida, "PV \& Peltier façade: Preliminary experimental results," Energy Procedia, vol. 78, pp. 3477-3482, 2015. 
13. R. Daghigh and Y. Khaledian, "Effective design, theoretical and experimental assessment of a solar thermoelectric cooling-heating system," Sol. Energy, vol. 162, no. October 2017, pp. 561-572, 2018.

14. A. Prieto, U. Knaack, T. Auer, and T. Klein, "Solar coolfacades: Framework for the integration of solar cooling technologies in the building envelope," Energy, vol. 137, pp. 353-368, 2017.

15. B. McNelis, "CHAPTER 11 - PHOTOVOLTAIC REFRIGERATION," in Renewable Energy, A. A. M. SAYIGH and J. C. B. T.-S. A. C. and R. McVEIGH, Eds. Oxford: Pergamon, 1992, pp. 268289.

16. A. Zuazua-Ros et al., "CHAPTER 11 PHOTOVOLTAIC REFRIGERATION,” Sol. Energy, vol. 22, no. 1, pp. 376-393, 2018.

17. D. Enescu, A. Ciocia, A. Mazza, and A. Russo, "Solutions based on thermoelectric refrigerators in humanitarian contexts," Sustain. Energy Technol. Assessments, vol. 22, pp. 134-149, 2017.
18. N. Aste, C. Del Pero, and F. Leonforte, "Active refrigeration technologies for food preservation in humanitarian context - A review," Sustain. Energy Technol. Assessments, vol. 22, pp. 150-160, 2017.

19. K. O. Daffallah, M. Benghanem, S. N. Alamri, A. A. Joraid, and A. A. Al-Mashraqi, "Experimental evaluation of photovoltaic DC refrigerator under different thermostat settings," Renew. Energy, vol. 113, pp. 1150-1159, 2017.

20. R. L. Field, P. Carrasco, and C. A. de Quadros, "Review of photovoltaic-powered refrigeration for medicines in developing countries," Sol. Cells, vol. 6, no. 3, pp. 309-316, 1982. 